\title{
Study on the Influence of Chloride Ions Content on the Sea Sand Concrete Performance
}

\author{
Wu Sun, Junzhe Liu ${ }^{*}$, Yanhua Dai, Jiali Yan \\ School of Civil Engineering, Ningbo University, Ningbo, Zhejiang, China
}

Email address:

491480031@qq.com (Wu Sun), junzheliu@163.com (Junzhe Liu), 963122649@qq.com (Jiali Yan),759782287@qq.com (Yanhua Dai)

*Corresponding author

\section{To cite this article:}

Wu Sun, Junzhe Liu, Jiali Yan, Yanhua Dai. Study on the Influence of Chloride Ions Content on the Sea Sand Concrete Performance. American Journal of Civil Engineering. Vol. 4, No. 2, 2016, pp. 50-54. doi: 10.11648/j.ajce.20160402.12

Received: February 27, 2016; Accepted: March 9, 2016; Published: March 23, 2016

\begin{abstract}
The influence of chloride ions content on the sea sand concrete performance was investigated through testing the sea sand mortar strength in this paper. The concrete strength rule was analyzed to discover the early strength for the sea sand concrete by the presence of chloride. In addition, the XRD microscopic analysis and TG/DTA were observed the composition of concrete to research the influence on hydration processes of concrete caused by sea sand, and from two aspects to find out the differences of the internal microcosmic structure and the chemical composition respectively. And Micro-technique was used to determine the water-soluble chloride ion concentration of different types of sea sand concrete which were maintained 28 days. The results show that the chloride ion can improve concrete strength value and the concentration of free chloride increases with the rise of extraction temperature.
\end{abstract}

Keywords: Sea Sand Mortar, Water Soluble Chloride Ions, Micro Structures

\section{Introduction}

Sea sand concrete is a kind of concrete in which mixed sea sand as fine aggregate, which is large-scale application in the coastal areas and gets more and more attention of the researchers in recent years [1], especially in Ningbo area. The sea sand solves the problem of river sand shortage [2-6]. Therefore, scientific, standardized and reasonable use of local resources of sea sand concrete is of great practical significance to the local economic development. [7]

Generally, there are three types of chloride ions in the sea sand concrete: free chloride ions, physically bound and chemically bound chloride ions. Only the first type is responsible for the corrosion of rebars. Even though the $\mathrm{pH}$ of concrete is more than 12 , the free chloride ions accumulated on the surface ofrebars can cause or aggravate the corrosion [8-9].

The history of using sea sand in China is very short, so the durability of the sea sand concrete need to be tested by many projects in the future. The chloride ions in sea sand is the one of main reasons which cause the concrete reinforcement corrosion. So in order to get a fine durability concrete, this paper clarified the actionmechanism of chlorine ions in sea sand concrete, as well as the effects of internal microstructure of concrete and material compositions.

\section{Experimental Procedure}

\subsection{Materials and Mix Proportions}

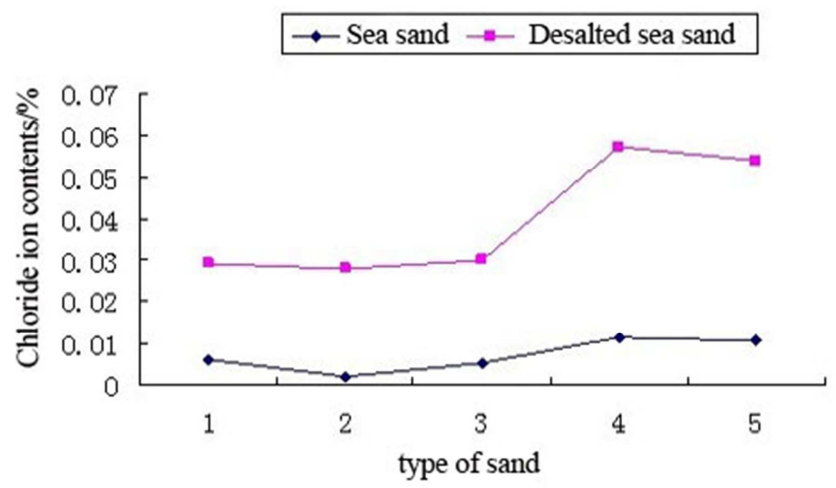

Figure 1. Chloride ion contents in sea sand (W\%). 
Grade 42.5 ordinary Portland cement produced by Ningboshunjiang Cement Plant was used in this study; River sand (RS) was used as fine aggregate, and its fineness modulus is 2.27. Regular sea sand (SS) and desalted sea sand (DSS) came from five plants and its chloride ion contents are shown in Figure 1.

Mixture proportions are shown in table 1. The mortar cube specimens of $70.7 \mathrm{~mm} \times 70.7 \mathrm{~mm} \times 70.7 \mathrm{~mm}$ were prepared and tested after being cured in standard curing room for 28 days.

Table 1. Mix proportions of the mortar.

\begin{tabular}{llll}
\hline Sample & Sand type & $\mathbf{C l}^{-}$contents in sand (\%) & $\begin{array}{l}\text { Mix proportion } \\
(\mathbf{C}: \mathbf{S}: \mathbf{W})\end{array}$ \\
\hline HCA & RS & 0.01 & $1: 2.5: 0.45$ \\
HCB & RS & 0.06 & $1: 2.5: 0.45$ \\
D & DSS & 0.01 & $1: 2.5: 0.45$ \\
W & SS & 0.054 & $1: 2.5: 0.45$ \\
\hline
\end{tabular}

* RS-River sand

\subsection{Test Method}

\subsubsection{Test of Sea Sand Mortar Strength}

Different types of sea sand mortar were prepared according to JTJ 270-1998 testing code of concrete for port and waterwog engineering.

\subsubsection{Test of Product Analysis and Microstructure of Mortar}

The proportions of three samples HCA, HCB, W, Dfor TG/DTA and XRD tests were shown in Table 1. The mortar used for the SEM test was mixed with regular sea sand. The scanning electron microscope was produced by Japan Hitachi Company. The polycrystalline X-ray diffraction and TG/DTA thermal analyzer were produced by German Brueck and America Perkin Amelmer Company. The inner products, microstructure and its content in mortars can be determined by use of these analyzers.

\subsubsection{Test of Total Chloride Content in Regular Sea Sand and Desalted Sea Sand}

The sand was quartered to $1500 \mathrm{~g}$ and dried in an oven with $105^{\circ} \mathrm{C}$. Then the sand was cooled to room temperature. $500 \mathrm{~g}$ sand was put in a reagent bottle with rubber stopper then $500 \mathrm{ml}$ distilled water was added. For the complete extraction of chloride in sand, the bottle was vibrated once in $24 \mathrm{~h}$ and thereafter three times every five minutes. After a certain time, the clear solution in the bottle was filtered and let the filtrate flow into a glass beaker. $50 \mathrm{ml}$ filtrate was transferred into a triangular flask by pipette. Then the filtrate was titrated by $0.01 \mathrm{~mol} / \mathrm{L}$ standard silver nitrate solution with $5 \%$ potassium chromate as indicator until the solution become red and the red color can be maintained for 5-10s. In the course of titration, the amount of standard silver nitrate solution consumed was recorded and the total chloride content in sea sand can be calculated according to the amount.

\subsubsection{Test of Free Chloride Ion Content in Mortar}

The motar cubes were cured at the standard condition for 28 days. The mole method was adopted to test the free chloride ion content. The $\mathrm{pH}$ of the solution under the test must be near neutral according to the requirement of mole method, however, the solution of mortar is alkaline. The dilute sulfuric acid was used for the neutralization in this study.

To investigate the effect of extraction temperature on the total or free chloride concentration of mortar, the tests of chloride ion content were carried out at $15^{\circ} \mathrm{C}$ and $65^{\circ} \mathrm{C}$, respectively.

\section{Experimental Results and Discussion}

\subsection{The Influence of Chlorine Salt Content on the Sea Sand Concrete Strength}

Figure 2 and 3 shows no obvious regularity of between chlorine salt content and sea sand concrete strength. But simply fromgoup D and $\mathrm{W}$, it can be foundthat higher sea sand concrete strength in higher chlorine salt content.It may be for two reasons, one reason is that the chloride ion can improve concrete strength value, another isthat the grading of not desalinate sea sand is slightly better than the grading of desalination sea sand.

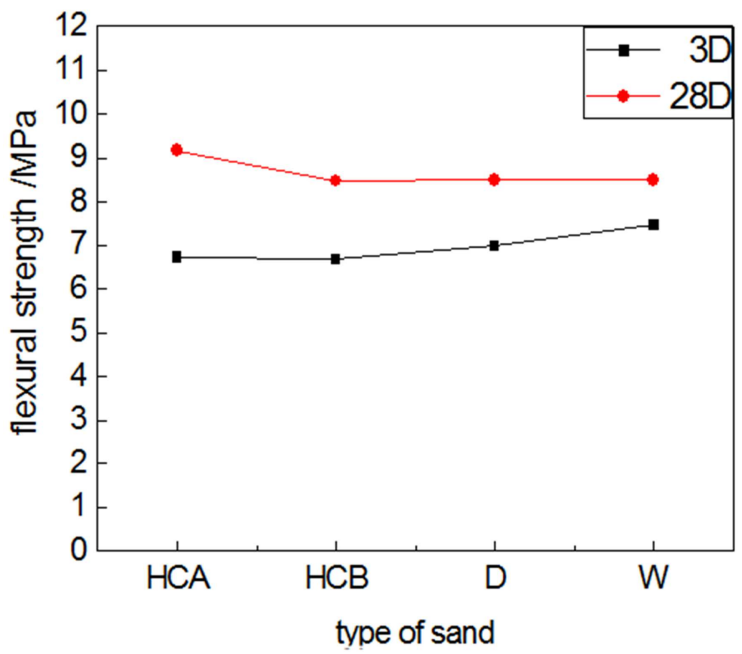

Figure 2. Sea sand mortar flexuralstrength (MPa).

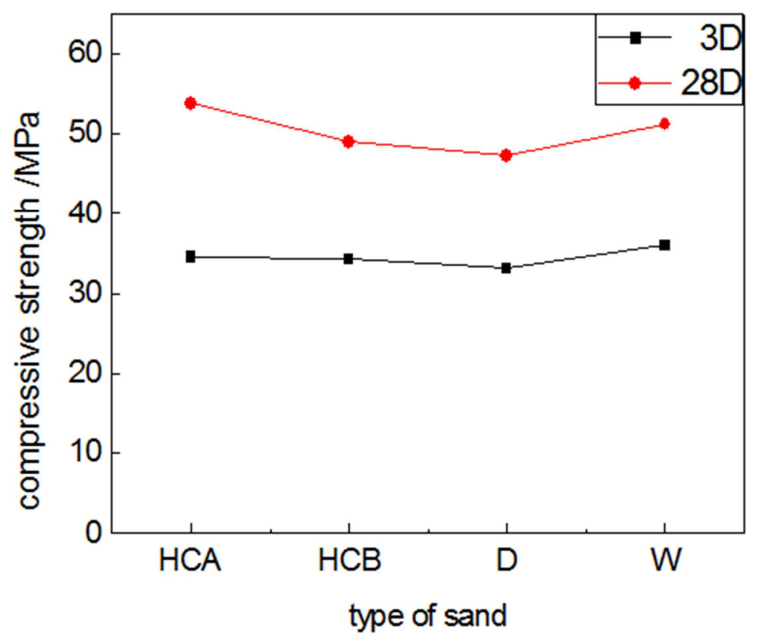

Figure 3. Sea sand mortar compressive strength (MPa). 


\subsection{Free Chloride Ion Content in Mortar}

\subsubsection{Total Chloride Ion Content in Regular Sea Sand and Desalted Sea Sand}

Figure 1 shows chloride ion contents of samples derived from the five plants are different.The chloride ion content in desalted sea sand is significantly lower than regular sea sand. It also shows that the the higher the original chloride ion content, the higher the residual content is after the sea sand is desalted.

\subsubsection{Free Chloride Ion Content in Sea Sand Mortar}

Figure 4 shows the soluble and bonded chloride ion contents at $15^{\circ} \mathrm{C}$ and $65^{\circ} \mathrm{C}$ in mortars. It can be seen that there is a close correlation between free chloride concentration and extraction temperatures. At $15^{\circ} \mathrm{C}$, free chloride concentration content varies from $22 \%-34 \%$ and at $65^{\circ} \mathrm{C}$, it varies from $52 \% \sim 65 \%$. This indicates that the free chloride concentration of mortars at extraction temperature $65^{\circ} \mathrm{C}$ is about twice as mortars at $15^{\circ} \mathrm{C}$. This may be due to that the extraction rate of physically bound chloride ion increase with an increase in temperature. Therefore, taking the differential between total chloride ion content and free chloride ion content as the amount of chemically bound chloride is somewhat inaccurate.

There are physically and chemically bound chloride ions in mortars. Chemical bonding generally results from the reaction between chlorides and C3A to produce Friedel's salt or the reaction with C4AF to produce a Friedel's salt analogue. Physical binding is owing to the adsorption of chloride ion to the C-S-H surfaces.

Majority of the chloride ion is in the form of physically bound to ion exchange sites of C-S-H gel and there exists a significant degree of reversibility. In fact, for a physical adsorption, an increased temperature accelerates the thermal vibration of absorbates, bring about more free chloride.

In addition, Figure 5 shows the free chloride extraction rate of the mortar with $20 \%$ fly ash is higher than that of the cement mortar without fly ash at extraction temperature $15^{\circ} \mathrm{C}$, however, the free chloride extraction rate of the mortars with or without fly ash is almost the same at extraction temperature $65^{\circ} \mathrm{C}$. This may be due to less chemical bound and more physical bound chloride ions at lower extraction temperature.

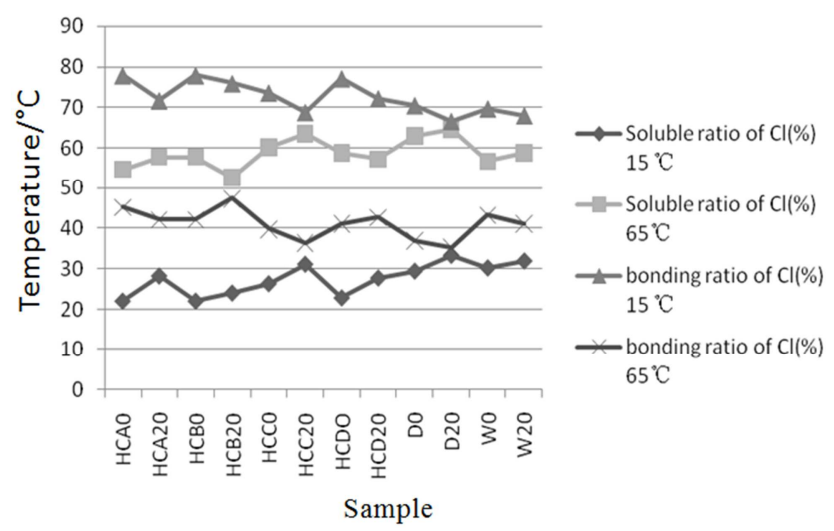

Figure 4. Existing status of chloride ions at different temperatures.

\subsection{The Characteristic of Friedel's Salt in Sea Sand Mortar}

As chloride enters the cementitious material, it may be converted to Friedel's salt due to chemical binding. Chloride ion can be introduced into concrete by two methods: (1) mixingas an additional agent (internal chloride); (2) penetrating from outside (external chloride). In the literature review, the chloride was frequently dissolved in the mixing water and then entered the mixture. At the same time, the amount of chloride introduced varies $2 \% \sim 10 \%$ by weight of the cementitious material. Many researchers investigated the Friedel's salt with the above mentioned condition. However, because the chloride contents in the regular sea sand and desalted sea sandare much lower than that of abovementioned researches, it has not been reported if the Friedel's salt exsits in regular sea sand or desalted sea sand mortars and concretes and if it can be observed [10].

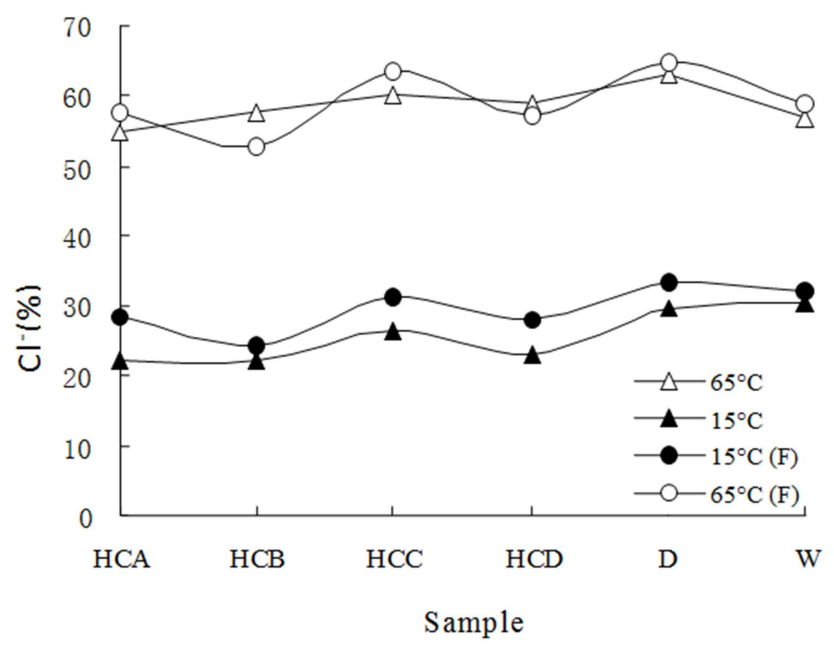

Figure 5. Relationship between the temperature and soluble chlorideion concentrations.

Generally, Friedel's salt yields an endothermal effect at about $360^{\circ} \mathrm{C}[11,12]$. Figure 6 shows the TG/DTA curves of mortars with river sand (sample HCD0), regular sea sand (sample W0) and desalted sea sand (sample D0), and the chloride content of these sands were $0.1 \%, 0.054 \%$ and $0.01 \%$, respectively. Unfortunately, no clear endothermal peaks of Friedel's salt appear for the three TG/DTA curves of mortars.

To further clarify weather Friedel's salt exists in regular sea sand and desalted sea sand mortar, the XRD tests were carried out for the grounded mortars samples at 28 days of age and the results are shown in Figure 7. From Figure 7, regardless of the mortars with regular sea sand or desalted sea sand, several intensity peaks of Friedel's salt come ourat the corresponding situation. However, the intensity peak of the Friedel's salt is quite lower than the other compositions (for example $\mathrm{Ca}(\mathrm{OH})_{2}$ ) of the mortar. This indicates that the chloride ions introduced by regular sea sand or desalted sea sand still form some Friedel's salt in the mortars. 


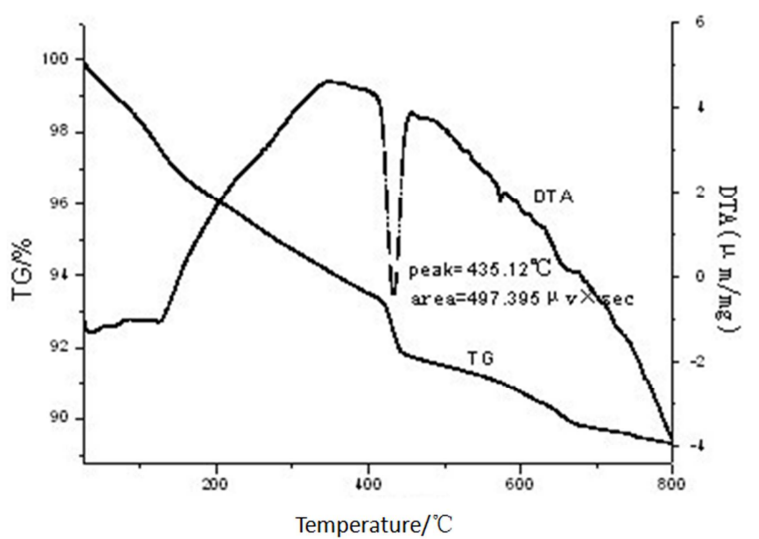

(a) TG/DTA curves of D

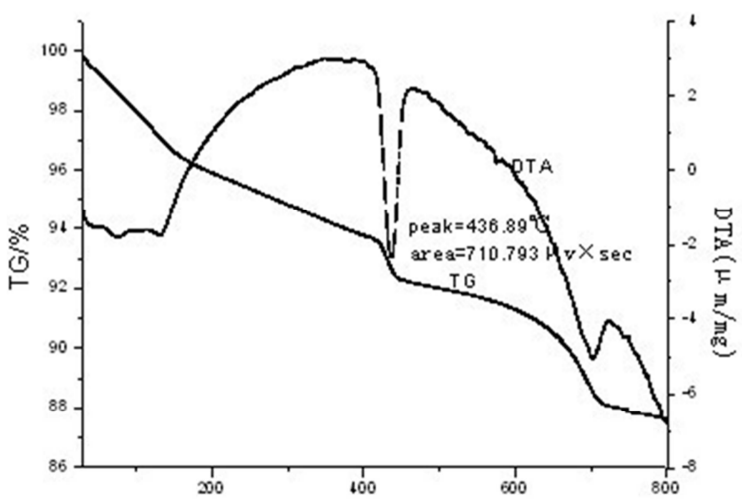

Temperature/ ${ }^{\circ} \mathrm{C}$

(b) TG/DTA curves of D

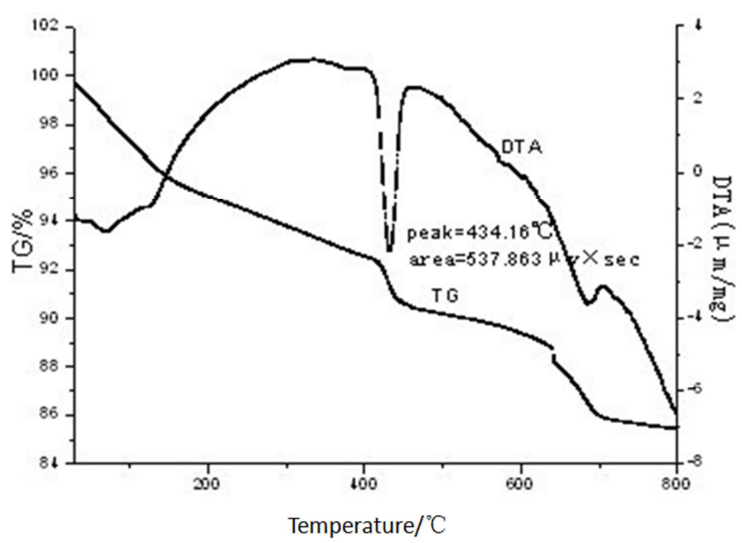

(c) TG/DTA curves of W

Figure 6. TG/DTA curves of mortar

Because the total chloride content in regular sea sand or desalted sea sand is relatively low, the intensity peak of Friedel's salt is very low. Moreover, the abovementioned TG/DTA curves of mortars do not show the end other mal peak of Friedel's salt. This is because the small amount of chloride ions introduced by regular sea sand or desalted sea sand formed a very small amount of unstable Friedel's salt. In this paper, the intensity peak of Friedel's salt can be clearly observed in the mortars with river sand containing more than $0.03 \%$ chloride content, and not in the mortars with river sand containing less than $0.03 \%$ chloride content.

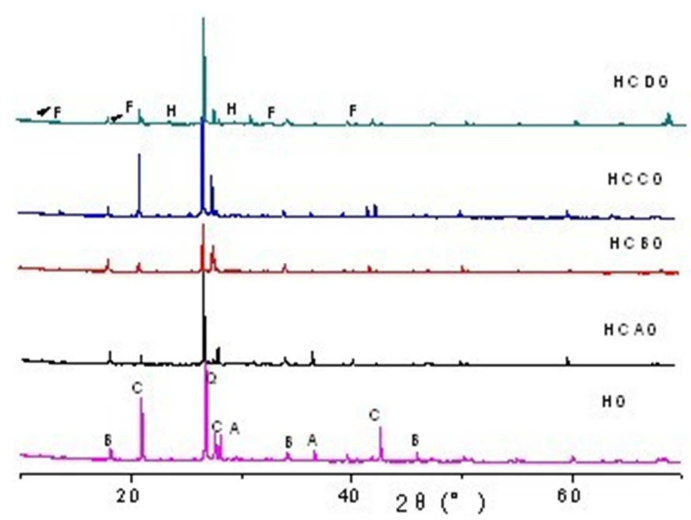

(a) XRD patterns of mortars with river sand

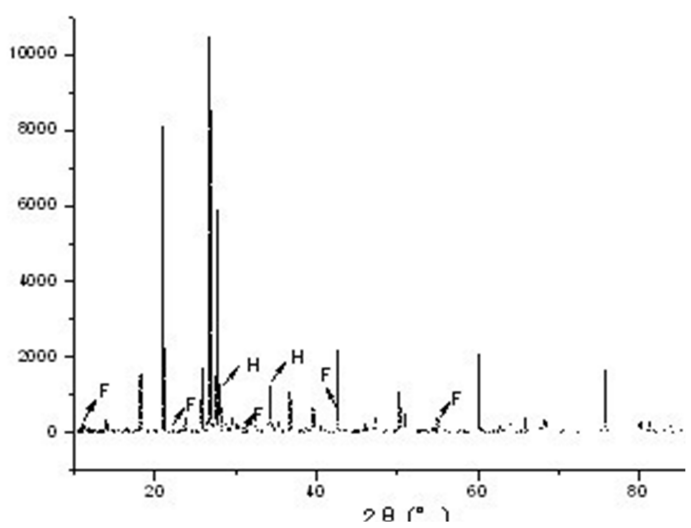

(b) XRD patterns of mortars with desalted sea sand

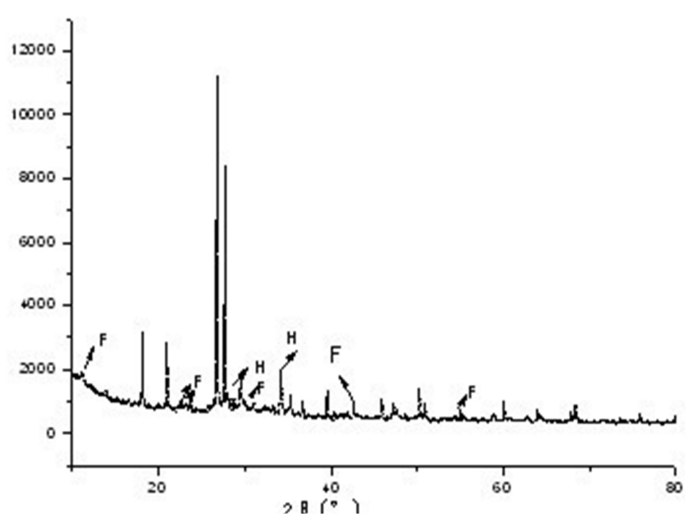

(c) XRD patterns of mortars with sea sand

Figure 7. XRD patterns of mortars.

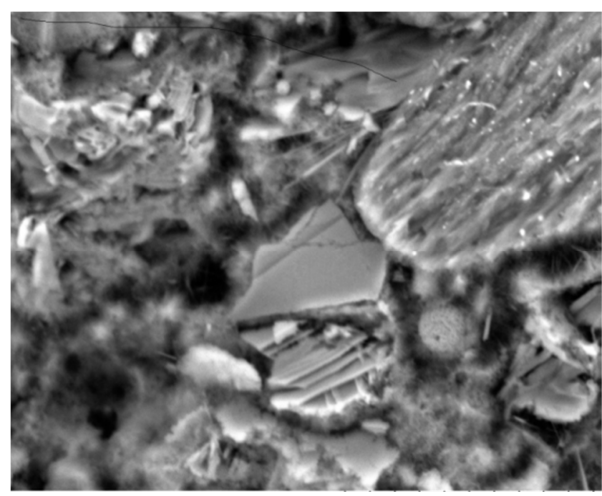

Figure 8. SEM micrographs of Friedel's salt. 
The SEM micrographs of Friedel's salt in regular sea sand mortars is showed by Figure 8. It is clear to see that Friedel's salt's morphology is hexagonal slice in size of about $2 \sim 3 \mu \mathrm{m}$. Base on the investigation of XRD and SEM, we can conclude that Friedel's salt exisits in sea sand mortars.

\section{Conclusions}

(1) The chloride ion can improve concrete strength value.

(2) Regardless of the mortars with river sand, regular sea sand or desalted sea sand, the free chloride content correlates closely to the extraction temperature. The concentration of free chloride increases with the rise of extraction temperature, and the free chloride concentration increases by about two times when the extraction temperature varies from $15^{\circ} \mathrm{C}$ to $65^{\circ} \mathrm{C}$.

(3) The free chloride concentration of the mortar with fly ash is higher than that of the mortar without fly ash at 15 extraction temperature. This may be due to the chemically bound chloride ion content is low and the physically bound chloride ion content is relatively high.

(4) Small quantity of unstable Friedel's salts exists in the mortars. It explains why the TG/DTA curves of regular sea sand and desalted sea sand mortars do not show end other mal peaks. Thus, it is unreasonable to determine the existence of Friedel's salt only using TG/DTA curves, and the invest igation of XRD and SEM should be carried out at same time.

\section{Acknowledgements}

This work has been supported by K. C. Wong Magna Fund in Ningbo University, the National Natural Science Foundation of China (No. 51278255, 51478227) and Ningbo Municipal Science and Technology Project (No. 2013C51006).

\section{References}

[1] QI Gui-hai, WANG Yu-lin, LI Shuo, WANG Zhang-li. Review on sea sand concrete research in China. Concrete, 2013, 557-61.
[2] S. Pack, M. Jung, H. Song, S. Kim, K. Ann. Prediction of time dependent chloride transport in concrete structures exposed to a marine environment. Cement and Concrete Research, 2010, 40(2) 302-312.

[3] J. J SHI, W. SUN. Recent research on steel corrosion in concrete Chinese Ceramic Society, 2010, 38(9) 1753-1764.

[4] Q. Yuan, C. J. Shi, G. D. Schutter, K. Audenaert, D. H. Deng. Chloride binding of cement-based materials subjected to external chloride environment-A review. Construction and Building Materials, 2009, 23(1) 1-13.

[5] K. V. Subramaniam, M. D. Bi. Investigation of steel corrosion in cracked concrete: Evaluation of macrocell and microcell rates using Tafel polarization response. Corrosion Science, 2010, 52(8) 2725-2735.

[6] Jianbin Chen,Junzhe Liu, Guoliang Zhang, Zhimin He. Study on the strength of sea sand concrete introduced by chloride ions, 2011 Second International Conference on Mechanic Automation and Control Engineering, 2011, 250-253 262-265.

[7] S. HE. The application of desalination sea sand in commercial concrete. Fujian Building Materials, 2013, 11 45-46.

[8] Z. Q. JIN, W. SUN, T. J. ZHAO, Q. Y. LI. Chloride binding in concrete exposed to corrosive solutions. Chinese Ceramic Society, 2009, 37(7) 1068-1072.

[9] S. M. Abd El Haleem, S. Abd El Wanees .Environmental factors affecting the corrosion behavior of reinforcing steel. IV. Variation in the pitting corrosion current in relation to the concentration of the aggressive and the inhibitive anions. Corrosion Science, 2010, 52(5) 1675-1683.

[10] J. Z. LIU, F. XING, Z. M. HE, Z. DING. Study on critical value of $\mathrm{n}\left(\mathrm{NO}_{2}^{-}\right) / \mathrm{n}\left(\mathrm{Cl}^{-}\right)$in reinforced concrete. Chinese Ceramic Society, 2010, 38(4) 68-73.

[11] C. Abate, B. E. Scheetz. Aqueous phase equilibria in the system $\mathrm{CaO}-\mathrm{Al}_{2} \mathrm{O}_{3}-\mathrm{CaCl}_{2}-\mathrm{H}_{2} \mathrm{O}$ : The significance and stability of Friedel's salt. Journal of American Ceramic Society, 1995, 78(4) 939-944.

[12] Rafael Talero. Synergic effect of Friedel's salt from pozzolan and from OPC co-precipitating in a chloride solution. Construction and Building Materials, 2012, 33(8) 164-180. 